\title{
Empiric Study of Ship Maintenance Price Index based on The Hedonic Model
}

\author{
Jungang $\mathrm{Du}^{\mathrm{a}}$, Dong Huang ${ }^{\mathrm{b}}$ \\ School of Naval Univ. of Engineering, Wuhan 430033, China \\ ajungangdu225@sina.com, bhuang-d@126.com.
}

Keywords: Ship maintenance, heterogeneity characteristic, hedonic price index.

\begin{abstract}
Because the pure-exemplar matching method settles the ship maintenance price index compilation unavailingly due to the heterogeneity characteristics of the ship maintenance activities, the hedonic price theory is put forward into this paper, and the hedonic model of ship maintenance price is established with the combinated data modeling method. And then the hedonic price index of ship maintenance is obtained through this model. Finally, this hedonic price index is compared with the aftermath calculated on pure-exemplar matching method.
\end{abstract}

\section{Introduction}

For the ship maintenance price index compilation research, the USA et.al developed country had formulated some economic indicators to adjust the ship maintenance price during different years, such as dedicated inflation rate and Gelfei index ${ }^{[1]}$. Based on the statistical material, the Chinese scholar used the pure-exemplar matching method to complicate the ship maintenance price index ${ }^{[2]}$. The characteristics of the commodity or service activities are required to be invariant in this method, to reflect the pure-price change of the commodity or service. But the impact elements to ship maintenance price lead to the heterogeneity characteristics of the ship maintenance activities. If the quality of sample is not to be adjusted, the ship maintenance price index complicated on the original data would not really reflect the change features of ship maintenance price.

Therefore, the hedonic price theory is put forward into this paper, and the hedonic model of ship maintenance price is established with the combinated data modeling method. And then the hedonic price index of ship maintenance is obtained through this model. Finally, this hedonic price index is compared with the aftermath calculated on pure-exemplar matching method.

In the actual application, there are four basic hedonic models ${ }^{[3]}$, such as linear regression, Log-Log regression, Semi-Log regression and Log-Linear regression ${ }^{[4]}$. And the linear regression and Log-Linear regression are the common-used model ${ }^{[5]}$.

The linear regression model is

$$
P=\alpha_{0}+\sum \alpha_{i} x_{i}+\varepsilon_{i} \quad \varepsilon_{i} \sim N\left(0, \sigma^{2}\right) \quad i=1,2, \ldots, n
$$

The Log-Linear regression model is

$$
L n P=\alpha_{0}+\sum \alpha_{i} x_{i}+\varepsilon \quad \varepsilon_{i} \sim N\left(0, \sigma^{2}\right) \quad i=1,2, \ldots, n
$$

\section{Selection and Quantification of Ship Maintenance Hedonic Characteristic}

The first work of ship maintenance price hedonic model is the selection and quantification of ship maintenance hedonic characteristic ${ }^{[6]}$. Among the factors of ship maintenance price, the ship technology level, tonnage, rank and round turn of maintenance and district difference all can be selected as the hedonic characteristic of ship maintenance. The pure-price change index of ship maintenance cost caused by the price index can be analyzed through the virtual time variable, and the ship maintenance hedonic price index can be calculated through the parameter estimation of virtual time variable. But the ship maintenance cost sample is not large to modeling, so the combinated data modeling method was used in this paper ${ }^{[7]}$. 
Table 1 Quantification principle of each hedonic

\begin{tabular}{ccc}
\hline Hedonic & Unit & Data range \\
\hline $\begin{array}{c}\text { technology } \\
\text { level } \\
\text { tonnage }\end{array}$ & Ten-thousand/ton & $x_{1}>0$, continuous change \\
rank and turn & ton & $x_{2}>0$, continuous change \\
district & virtual & dock repair $x_{3}=0,1,2,3,4$; minor repair $x_{4}=0,1,2,3$; overhaul \\
difference & virtual & depair $x_{5}=0,1$. \\
time variable & virtual & second year: $x_{8}=0$ or 1 ; third year: $x_{9}=0$ or $1 ; x_{8} * x_{9}=0$. \\
\hline
\end{tabular}

\section{Foundation of Ship Maintenance Hedonic Price Model}

Take the ship maintenance cost sample from 2012 to 2014 as the modeling data, and each hedonic value was calculated in table 2 .

Table 2 Description of ship maintenance cost and hedonic

\begin{tabular}{cccccccccccc}
\hline \multirow{2}{*}{ number } & \multirow{2}{*}{ cost } & \multirow{2}{*}{$x_{1}$} & $x_{2}$ & \multicolumn{3}{c}{ rank and turn } & \multicolumn{3}{c}{ district } & \multicolumn{3}{c}{ time variable } \\
\cline { 5 - 11 } & & & $x_{3}$ & $x_{4}$ & $x_{5}$ & $x_{6}$ & $x_{7}$ & $x_{8}$ & $x_{9}$ \\
\hline 1 & 170 & 41.617 & 2226 & 3 & 0 & 0 & 0 & 0 & 0 & 0 \\
2 & 654.5 & 40.976 & 2226 & 0 & 1 & 0 & 0 & 0 & 0 & 0 \\
$\ldots$ & $\ldots$ & $\ldots$ & $\ldots$ & $\ldots$ & $\ldots$ & $\ldots$ & $\ldots$ & $\ldots$ & $\ldots$ & $\ldots$ \\
25 & 99.280 & 28.364 & 1070 & 1 & 0 & 0 & 0 & 1 & 1 & 0 \\
26 & 105.655 & 28.832 & 1070 & 1 & 0 & 0 & 0 & 1 & 1 & 0 \\
\hline
\end{tabular}

\subsection{The Hedonic Model Foundation}

Take the sample of table 2 to the linear regression model, and the ship maintenance hedonic linear model can be got as (3).

$$
\begin{aligned}
& P=-65.802-20.153 x_{1}+0.517 x_{2}-54.577 x_{3}+208.245 x_{4}+617.135 x_{5}- \\
& 94.097 x_{6}-48.955 x_{7}+260.195 x_{8}+243.853 x_{9}
\end{aligned}
$$

And the estimate and test of each regression parameter was also showed in table 3.

Table 3 Estimate and test of each regression parameter

\begin{tabular}{ccccc}
\hline parameter & Estimated value & Standard deviation & t-Statistic & Prob. \\
\hline$\alpha_{0}$ & -65.802 & 306.031 & -0.215 & 0.833 \\
$x_{1}$ & -20.153 & 19.609 & -1.028 & 0.319 \\
$x_{2}$ & 0.517 & 0.269 & 1.918 & 0.073 \\
$x_{3}$ & -54.577 & 50.117 & -1.089 & 0.292 \\
$x_{4}$ & 208.245 & 161.387 & 1.290 & 0.215 \\
$x_{5}$ & 617.135 & 128.922 & 4.787 & 0.000 \\
$x_{6}$ & -94.097 & 106.027 & -0.887 & 0.388 \\
$x_{7}$ & -48.955 & 87.012 & -0.563 & 0.582 \\
$x_{8}$ & 260.195 & 83.760 & 3.106 & 0.007 \\
$x_{9}$ & 243.854 & 85.297 & 2.859 & 0.011 \\
R & 0.901 & Adjusted R-squared & 0.764 \\
R-squared & 0.812 & Akaike info criterion & 12.986 \\
F-statistic & 18.618 & Schwarz criterion & 13.470 \\
Prob(F-statistic) & 0.000 & Durbin-Watson stat & 2.333 \\
\hline
\end{tabular}


The t-Statistic and R-squared of model (3) was unsatisfactory, and the D-W value was larger than 2, there was heteroscedasticity in this model. So we should use the Log-Linear regression model.

Take the sample of table 2 to the Log-Linear regression model, and the ship maintenance hedonic Log-Linear model can be got as (4).

$$
\begin{aligned}
& \ln P=-2.377-0.810 \ln x_{1}+1.285 \ln x_{2}+0.139 x_{3}+1.1481 x_{4}+2.083 x_{5}+0.174 x_{6}+0.285 x_{7}+ \\
& 0.160 x_{8}+0.307 x_{9}
\end{aligned}
$$

And the estimate and test of each regression parameter was also showed in table 4.

Table 4 test of of model 4

\begin{tabular}{ccccc}
\hline parameter & Estimated value & Standard deviation & t-Statistic & Prob. \\
\hline$\alpha_{0}$ & -2.377 & 2.135 & -1.113 & 0.040 \\
$\ln x_{1}$ & -0.810 & 1.145 & -0.707 & 0.015 \\
$\ln x_{2}$ & 1.285 & 0.796 & 1.615 & 0.047 \\
$x_{3}$ & 0.139 & 0.110 & 1.268 & 0.023 \\
$x_{4}$ & 1.481 & 0.334 & 4.434 & 0.000 \\
$x_{5}$ & 2.083 & 0.283 & 7.362 & 0.000 \\
$x_{6}$ & 0.174 & 0.210 & 0.829 & 0.031 \\
$x_{7}$ & 0.285 & 0.175 & 1.631 & 0.036 \\
$x_{8}$ & 0.160 & 0.172 & 0.929 & 0.009 \\
$x_{9}$ & 0.307 & 0.179 & 1.715 & 0.026 \\
$R$ & 0.973 & Adjusted $R$-squared & 0.915 \\
$R$-squared & 0.946 & Akaike info criterion & 0.565 \\
$F$-statistic & 30.853 & Schwarz criterion & 1.049 \\
Prob(F-statistic $)$ & 0.000 & Durbin-Watson stat & 1.890
\end{tabular}

Test analysis

1) $\mathrm{D}-\mathrm{W}$ value test. The $\mathrm{D}-\mathrm{W}$ value of model (4) was 1.890 , so the heteroscedasticity was inexistence in model (4).

2) Variance homogeneity test. In the majority situation, the observed value distributed randomly around the linear line, which passed through the 0 , this condition can be showed as fig 1 .

3) Normality test of residual. The fig. 2 was Residual histogram, and fig. 3 was Residuals of the cumulative probability map. Through the two figures, we could say the residual satisfied the normal distribution.

\subsection{Calculation and analysis of ship maintenance price index}

In the model (4), the parameter of time variable in 2013 was 0.160 , this value in 2014 was 0.307 . If the ship maintenance price in 2012 was $P_{1}$, the price in 2013 was $P_{2}$, and the price in 2014 was $P_{3}$, according to the model (4), we could get this result: $\ln P_{2}-\ln P_{1}=0.160, \ln P_{3}-\ln P_{1}=0.307$.

So, if the 2012 was base year, the ship maintenance price index in 2013 and 2014 respectively was $L I_{2013}=\exp (0.160) \times 100=117.4, L I_{2014}=\exp (0.307) \times 100=135.9$.

\section{Summary}

As one mean to reflect the change of ship maintenance cost, the hip maintenance price index is the important standard to formulate and adjust the ship maintenance plan. The hedonic theory was put forward into this paper, and the hedonic model of ship maintenance price is established with the combinated data modeling method. And then the hedonic price index of ship maintenance is obtained through this model. Meanwhile, this method used in this paper can be popularized into the calculation other equipment price index. 


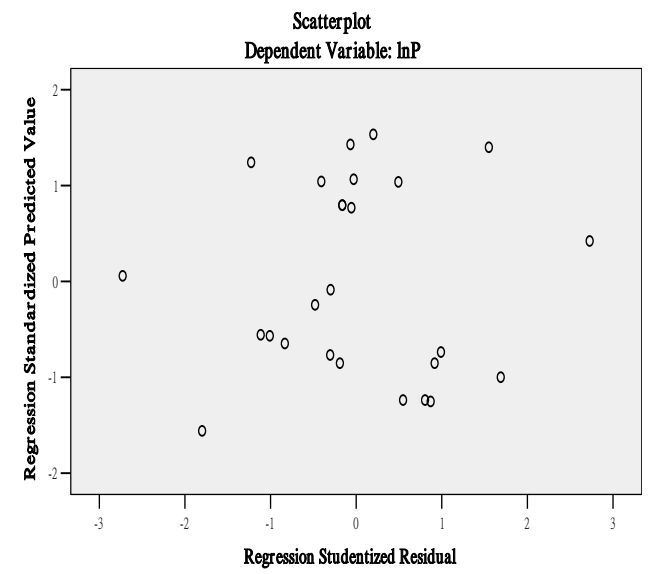

Fig. 1 Predictive value of the dependent variable and the residual scatter plot
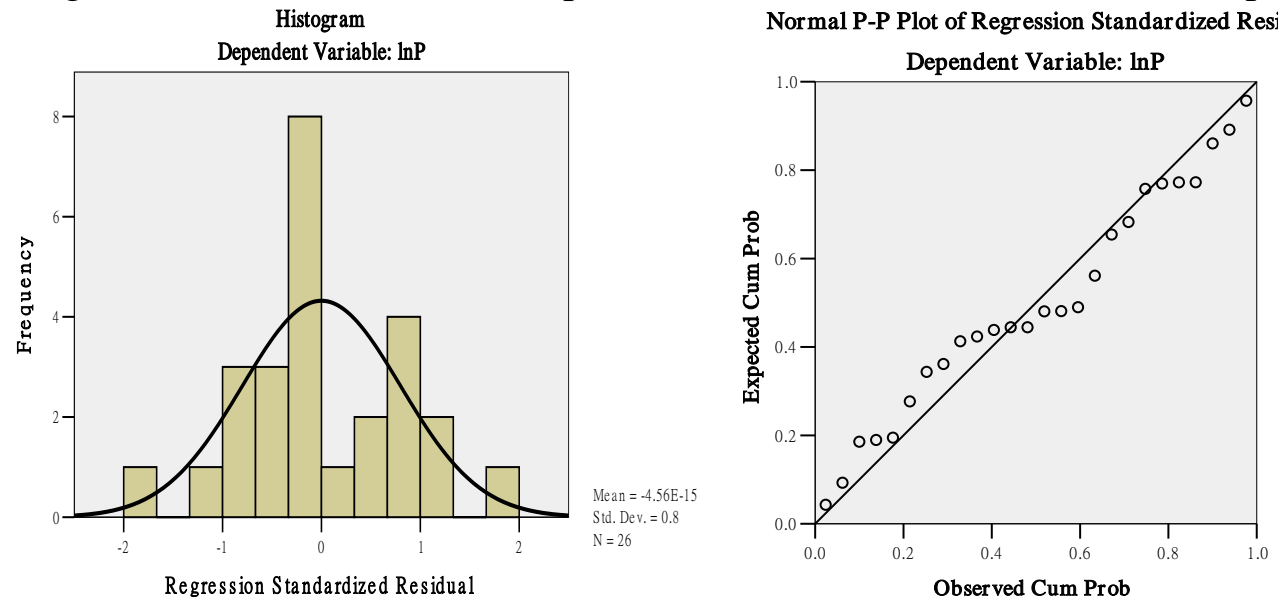

Fig. 2 Residual histogram

Fig. 3 Residuals of the cumulative probability map

\section{References}

[1]. Clinton P M, Brian C M \& Kenneth J. Stewart. A Reconciliation between the Consumer Price Index and the Personal Consumption Expenditures Price Index[R].Washington, DC: Bureau of Economic Analysis, 2006.

[2]. Liu Cheng Bin. Study on the Law of the Impact of Price Level Fluctuation upon Warship Equipment Maintenance Cost [D].Wuhan: Naval University of Engineering, 2009.

[3]. Diewert E. Hedonic Regression: A Consumer Theory Approach[R]. University of British Columbia, 2001.

[4]. Raimond M, Martin P, Steffen S Hedonic price indices for the paris housing market [J]. Allgemeines Statistisches Archiv., 2004, 88, 303-326.

[5]. Xibin Z, Maxwell L K. Box-Cox stochastic volatility models with heavy-tails and correlated errors [J]. Journal of Empirical Finance, 2008, 15(3): 549-566.

[6]. Brunauer W A, Lang S. Additive Hedonic Regression Models with Spatial Scaling Factors: An Application for Rents in Vienna [J]. The Journal of Real Estate Finance and Economics, 2010, 41(4): 390-411.

[7]. Tadao H, Koichi K. Measuring the Benefits of Neighbourhood Park Amenities: Application and Comparison of Spatial Hedonic Approaches [J]. Environmental and Resource Economics, 2010, 45(3): 429-444. 